\title{
Reconstruction with the use of autologous femoropopliteal veins for an infected aortobifemoral bypass graft
}

\author{
Jakub Kaczynski, ${ }^{1}$ Steve Atherton, ${ }^{2}$ Christopher G Davies, ${ }^{2}$ Colin J Ferguson ${ }^{3}$
}

${ }^{1}$ Vascular Surgery Department, ABM University Health Board, Swansea, UK

${ }^{2}$ ABM University Health Board, Swansea, UK

${ }^{3}$ Morriston Hospital,

Swansea, UK

\section{Correspondence to}

Jakub Kaczynski,

jakub.kaczynski@hotmail.co.uk
To cite: Kaczynski J, Atherton S, Davies CG, et al. BMJ Case Rep Published online: [please include Day Month Year] doi:10.1136/ bcr-2013-008586

\section{DESCRIPTION}

A 70-year-old man presented with left groin swelling 8 weeks after an aortobifemoral bypass graft (Dacron). The indication for an aortobifemoral bypass graft was a worsening short-distance claudication owing to an occluded aorta, right common iliac and left external iliac arteries (figure 1). His medical history included type 2 diabetes, hypertension, chronic obstructive pulmonary disease and atrial fibrillation. The patient was a non-smoker with alcohol consumption allowance below 21 units/week.

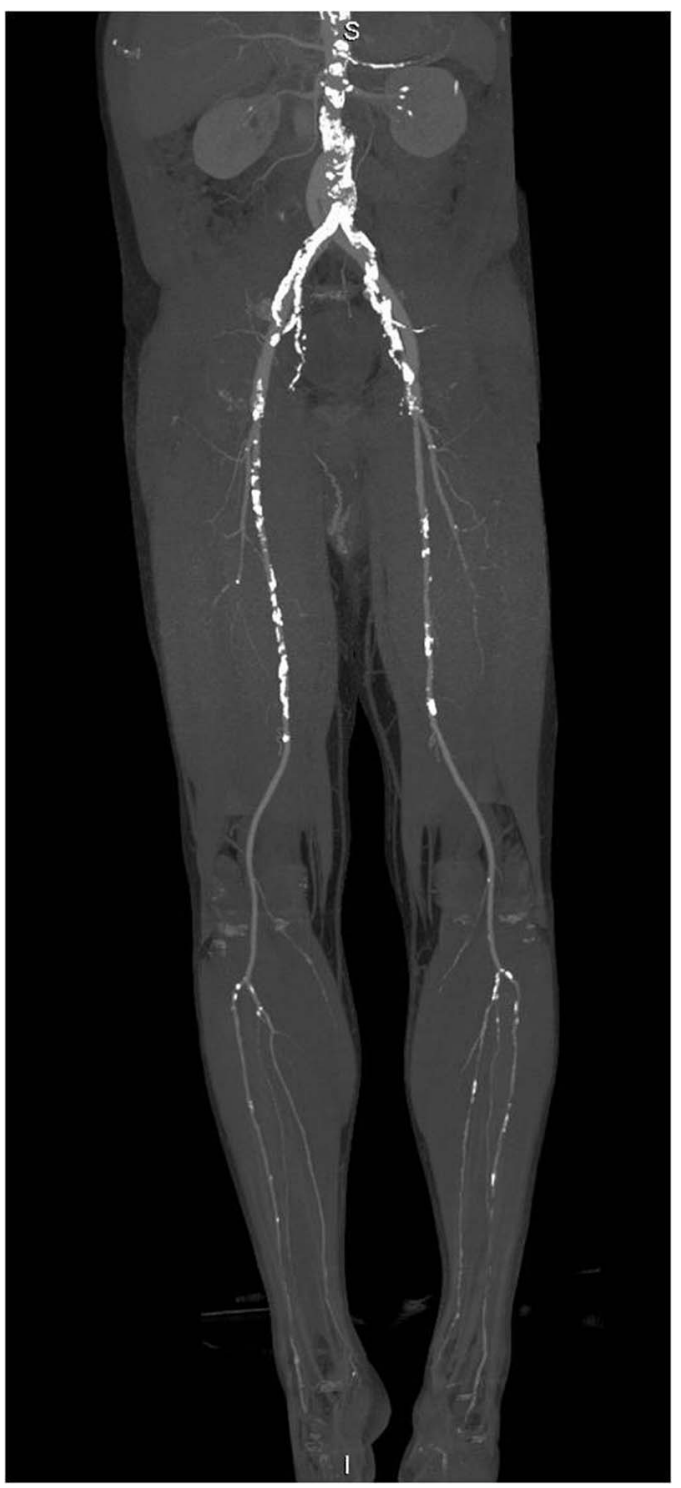

Figure $1 \mathrm{CT}$ angiography showing an aortoiliac disease.
Upon examination, the patient had a temperature of $38.4^{\circ} \mathrm{C}$ and a heart rate of $109 / \mathrm{min}$. Blood pressure and oxygen saturation were normal. Examination of respiratory system was unremarkable. Heart sounds were normal with no murmurs. Abdomen was soft and non-tender with healed scars. A detailed peripheral vascular examination demonstrated the left groin swelling with transmitted pulsation, which was not expansile. There was no tissue loss and pedal pulses were present bilaterally.

The patient was admitted, and an emergency ultrasound scan (US) of the left groin was performed to rule out the presence of pseudoaneurysm. The US showed reactive lymph nodes in the groin and heterogeneous collection $(1.8 \times 2.1 \mathrm{~cm})$ superiorly to the graft with no obvious flow within the collection. Subsequently, a CT angiography confirmed an isolated left groin collection (figure 2). Laboratory tests showed elevated white cell count (WBC) of $14 \times 10 \mathrm{~g} / \mathrm{l}$ and $\mathrm{C}$ reactive protein (CRP) of $102 \mathrm{mg} /$ 1. The remaining biochemical markers including liver function tests, amylase, urea and electrolytes and haemoglobin were within the normal range. A full septic screen was done including three sets of blood cultures, which were found to be negative after $48 \mathrm{~h}$ of incubation. A chest radiograph and midstream specimen of urine revealed no abnormalities. An aspiration of the left groin was deemed to be an unsafe option owing to the close proximity between the graft and collection. Therefore, following fluid resuscitation, high-dose broad-spectrum antibiotics were administered for the presumed prosthetic graft infection. The antibiotics included intravenous vancomycin $1 \mathrm{~g}$ daily with tazocin $4.5 \mathrm{~g}$ three times a day and oral doxycycline $200 \mathrm{mg}$ daily along with rifampicin $600 \mathrm{mg}$ twice daily and were

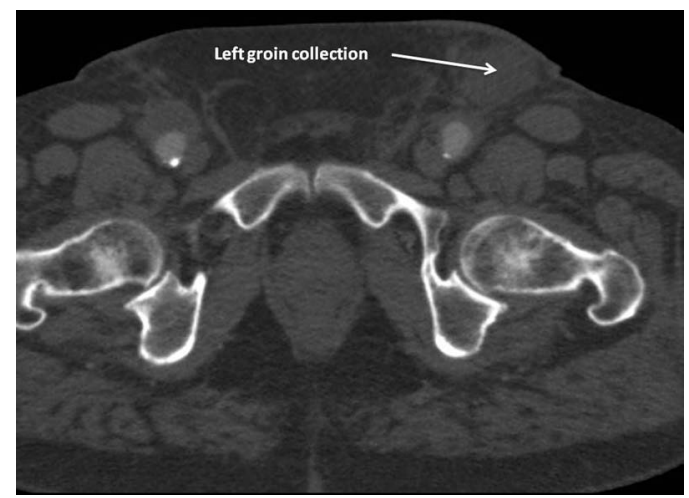

Figure 2 CT angiography demonstrating an isolated left groin swelling superior to the prosthetic graft. 


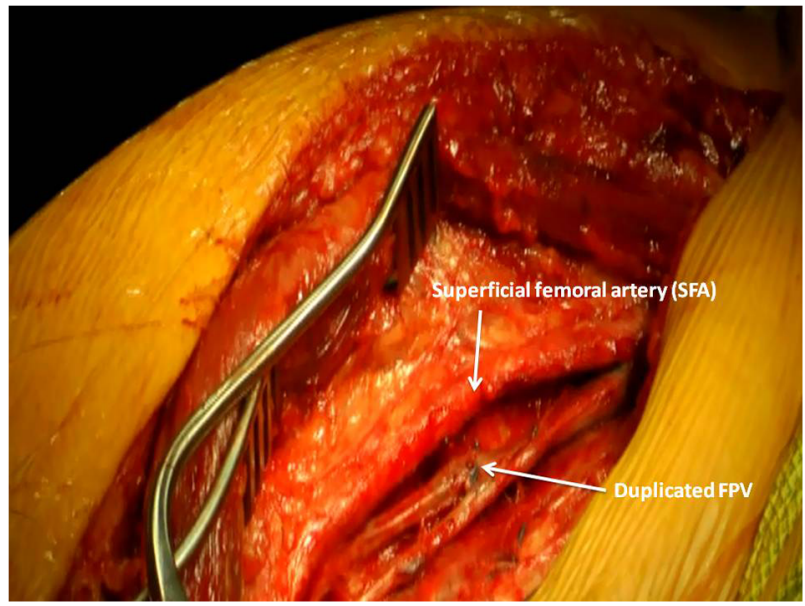

Figure 3 Right duplicated femoropopliteal vein harvest.

administered for 5 days preoperatively. In spite of that the patient continued to be febrile with rising levels of WBC and CRP. Therefore, after the discussion at the vascular multidisciplinary team meeting, it was decided that an excision of an infected aortobifemoral bypass graft with autologous veins reconstruction was the only feasible treatment option. Unfortunately, vein mapping of both lower and upper limbs revealed no suitable superficial veins. However, femoropopliteal veins (FPV) were found to be patent and with suitable diameters as venous conduits (8.2-9.9 $\mathrm{mm}$ diameters).

Subsequently, the patient underwent an explantation of an infected aortobifemoral bypass graft followed by an arterial reconstruction with bilateral FPV. Both FPV were harvested simultaneously by separate surgical teams from its origins to the adductor hiatus (figure 3). The third surgical team removed an infected aortobifemoral bypass graft and performed an aortobifemoral reconstruction (figures 4 and 5). This consisted of a proximal end-to-end aorto-FPV anastomosis (figure 6) and right distal end-to-side FPV-common femoral artery (CFA) anastomosis. Second FPV was anastomosed as an end-to-side anastomosis proximally onto the FPV (figure 7) and distally as an end-to-side anastomosis onto the left CFA. During the operation, a purulent fluid was discovered around the intra-abdominal portion of the graft as well as in the contralateral groin. The fluid was sent for a culture and sensitivity, but did not grow any pathogens. Postoperatively, the patient completed a 2 weeks course of broad-spectrum antibiotics and overall made an uneventful recovery.

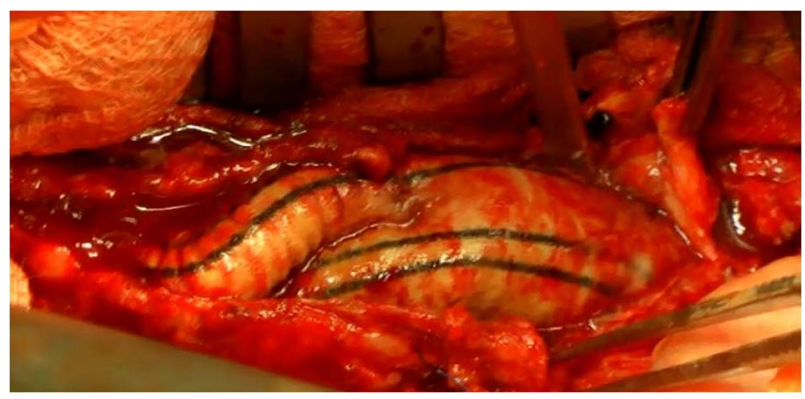

Figure 4 Dissected intra-abdominal portion of the aortobifemoral bypass graft.

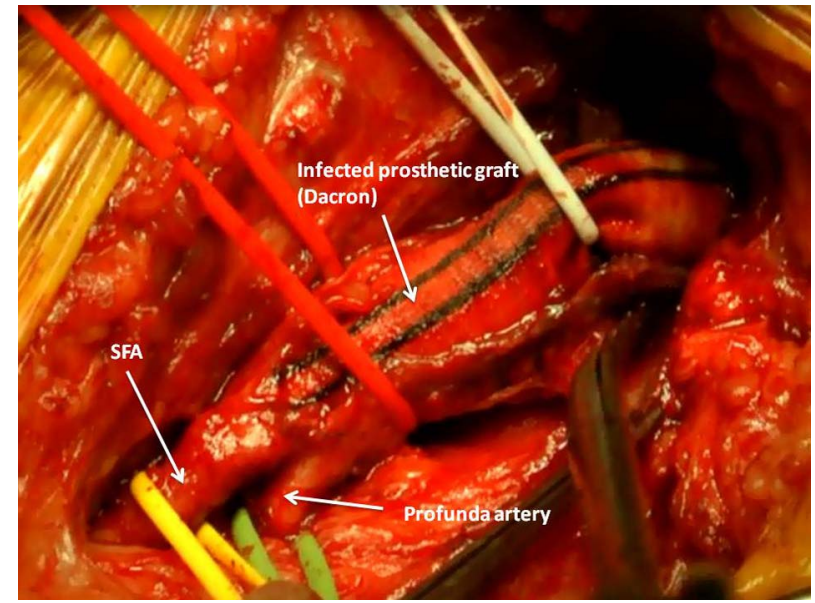

Figure 5 Dissected distal (groin) portion of the aortobifemoral bypass graft.

Routine graft surveillance scans showed a normal aorto-FPV anastomosis and static 50\% stenosis at the junction of the end-to-side FPV-FPV anastomosis with patent both limbs of the graft. Upon a routine follow-up appointment the patient reported no claudication and minimal lower limbs' swelling.

Graft infections following aortic reconstructions represent one of the most challenging conditions that vascular surgeons may deal with. The incidence varies from $0.7 \%$ to $2 \%$ and can be associated with a significant mortality of $25 \% .^{12}$ The core surgical principles advocate removal of an infected prosthetic material, meticulous debridement, prolonged antibiotic therapy followed by vascular reconstruction. ${ }^{1}$ The traditional treatment involves an infected graft excision followed by an extraanatomical or in situ bypass using an antibiotic-bonded prosthetic graft. ${ }^{3-5}$ However, this approach is associated with highreinfection rate (up to 25\%), aortic stump 'blow out', graft failures $(35 \%)$ and mortality of up to $30 \% .^{12}$ Also, the long-term results remain unknown. ${ }^{2} 6$ Another compelling alternative is the use of an autologous FPV as an arterial conduit in treatment of infected aortic grafts. FPV has been successfully used for many years as a form of reconstruction following various infrainguinal prosthetic graft infections. ${ }^{5}{ }^{7}$ Furthermore, some reported superior results with FPV use as a primary conduit for femoropopliteal bypasses. ${ }^{8-10}$

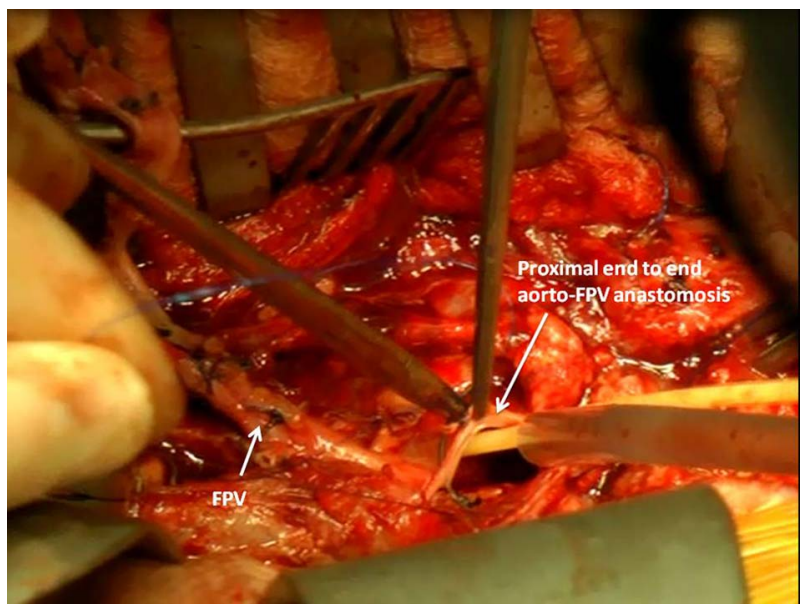

Figure 6 Proximal end-to-end aortofemoropopliteal vein anastomosis. 


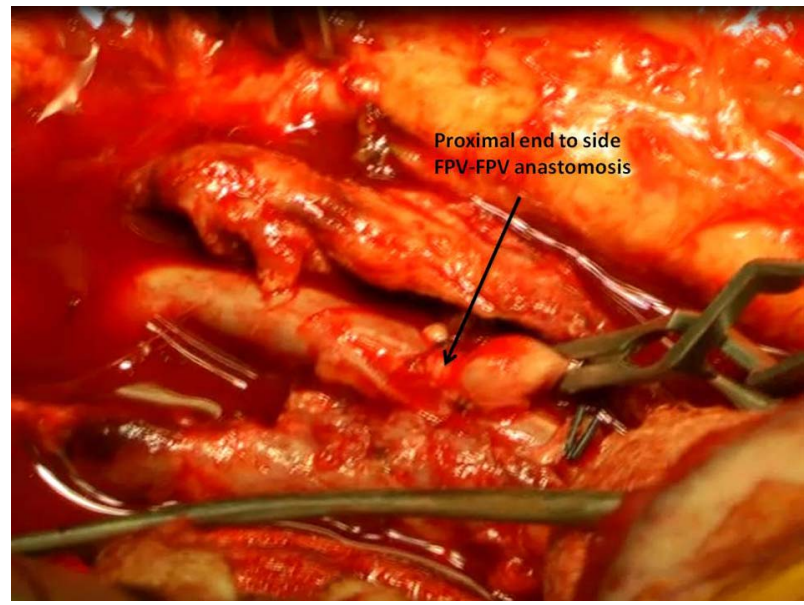

Figure 7 Proximal end-to-side femoropopliteal vein-femoropopliteal vein anastomosis.

Aortic reconstruction with FPV has many advantages. First, it allows for the restoration of an anatomical blood flow in the grossly contaminated area with high-patency rates. ${ }^{1}$ Second, death rates have been found to be significantly reduced $(4.3 \%){ }^{1}$ Finally, FPV almost eliminated recurrent infection. ${ }^{1}$ Despite that, there are some difficulties. One must remember that the length of the FPV available for harvesting is about $30-33 \mathrm{~cm}^{7}$ Consequently, both legs may require harvesting, which significantly prolongs the procedure. Also, the removal of the main venous trunks can lead to the chronic venous stasis. ${ }^{10} 11$ However, clinically this rarely causes a significant problem and more importantly, patients seem to well-tolerate FPV excision. ${ }^{12}$

Overall, FPV should be considered is a conduit of choice for an aortic reconstruction when there is a high-risk of a prosthetic graft infection.

\section{Learning points}

- The initial treatment of an infected aortic prosthetic bypass graft should include broad-spectrum antibiotics therapy.

- If the conservative approach fails, an extensive debridement of infected tissue with removal of an infected prosthesis followed by an arterial reconstruction is performed.

- The arterial reconstruction involves an extra-anatomical or an in situ bypass using an antibiotic-bonded prosthetic graft and an autologous femoropopliteal vein (FPV).

- FPV has been proved to produce satisfactory results and should be considered as a treatment of choice in the contaminated vascular fields.
Competing interests None.

Patient consent Obtained.

Provenance and peer review Not commissioned; externally peer reviewed.

\section{REFERENCES}

1 Ehsan 0, Gibbons CP. A 10-year experience of using femoro-popliteal vein for re-vascularisation in graft and arterial infections. Eur J Vasc Endovasc Surg 2009;38:172-9.

2 Thrush S, Watts A, Fraser SC, et al. Primary autologous superficial femoral vein reconstruction of an emergency, infected, ruptured aortic aneurysm. Eur J Vasc Endovasc Surg 2001;22:557-8.

3 Gibbons $C P$, Ferguson CJ, Fligelstone LJ, et al. Experience with femoro-popliteal vein as a conduit for vascular reconstruction in infected fields. Eur J Vasc Endovasc Surg 2003;25:424-31.

4 Gibbons CP, Ferguson CJ, Edwards K, et al. Use of superficial femoropopliteal vein for suprainguinal arterial reconstruction in the presence of infection. $\mathrm{Br} J$ Surg 2000;87:771-6.

5 Gibbons CP, Osman HY, Shiralkar S. The use of alternative sources of autologous vein for infrainguinal bypass. Eur J Vasc Endovasc Surg 2003;25:93-4.

6 Gupta AK, Bandyk DF, Johnson BL. In situ repair of mycotic abdominal aortic aneurysms with rifampin-bonded gelatin-impregnated Dacron grafts: a preliminary case report. J Vasc Surg 1996;24:472-6.

7 Kaczynski J, Gibbons CP. Experience with femoral vein grafts for infra-inguinal bypass. Eur J Vasc Endovasc Surg 2011:41:676-8.

8 Schulman ML, Badhey MR, Yatco R, et al. An 11-year experience with deep leg veins as femoropopliteal bypass grafts. Arch Surg 1986;121:1010-15.

9 Schulman ML, Badhey MR. Deep veins of the leg as femoropopliteal bypass grafts. Arch Surg 1981;116:1141-5.

10 Schulman ML, Badhey MR, Yatco R, et al. A saphenous alternative: preferential use of superficial femoral and popliteal veins as femoropopliteal bypass grafts. Am J Surg 1986;152:231-7.

11 Schulman ML, Schulman LG. Deep leg veins as femoropopliteal bypass grafts. World J Surg 1990;14:843-5. 
Copyright 2013 BMJ Publishing Group. All rights reserved. For permission to reuse any of this content visit http://group.bmj.com/group/rights-licensing/permissions.

BMJ Case Report Fellows may re-use this article for personal use and teaching without any further permission.

Become a Fellow of BMJ Case Reports today and you can:

- Submit as many cases as you like

- Enjoy fast sympathetic peer review and rapid publication of accepted articles

- Access all the published articles

- Re-use any of the published material for personal use and teaching without further permission

For information on Institutional Fellowships contact consortiasales@bmjgroup.com

Visit casereports.bmj.com for more articles like this and to become a Fellow 